\title{
The Role of Metabolomics in Current Concepts of Organ Preservation
}

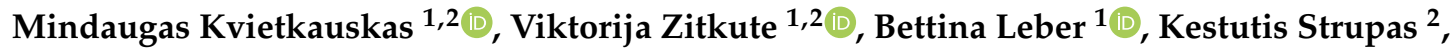 \\ Philipp Stiegler ${ }^{1, *}$ and Peter Schemmer ${ }^{1}$ \\ 1 General, Visceral and Transplant Surgery, Department of Surgery, Medical University of Graz, \\ Auenbruggerpl. 2, Graz 8036, Austria; min.kvietkauskas@gmail.com (M.K.); \\ viktorijazitkute@gmail.com (V.Z.); bettina.leber@medunigraz.at (B.L.); peter.schemmer@medunigraz.at (P.S.) \\ 2 Faculty of Medicine, Vilnius University, M. K. Ciurlionio 21, 03101 Vilnius, Lithuania; \\ kestutis.strupas@santa.lt \\ * Correspondence: philipp.stiegler@medunigraz.at; Tel.: +43-316-385-84094
}

Received: 12 July 2020; Accepted: 8 September 2020; Published: 10 September 2020

\begin{abstract}
In solid organ transplantation (Tx), both survival rates and quality of life have improved dramatically over the last few decades. Each year, the number of people on the wait list continues to increase, widening the gap between organ supply and demand. Therefore, the use of extended criteria donor grafts is growing, despite higher susceptibility to ischemia-reperfusion injury (IRI) and consecutive inferior Tx outcomes. Thus, tools to characterize organ quality prior to Tx are crucial components for Tx success. Innovative techniques of metabolic profiling revealed key pathways and mechanisms involved in IRI occurring during organ preservation. Although large-scale trials are needed, metabolomics appears to be a promising tool to characterize potential biomarkers, for the assessment of graft quality before Tx and evaluate graft-related outcomes. In this comprehensive review, we summarize the currently available literature on the use of metabolomics in solid organ Tx, with a special focus on metabolic profiling during graft preservation to assess organ quality prior to Tx.
\end{abstract}

Keywords: transplantation; machine perfusion; metabolomics; preservation; static cold storage

\section{Introduction}

Solid organ transplantation (Tx) is the only curative treatment option for patients suffering from end-stage organ failure. Liver, kidney, heart, lung and, to some extent, pancreas and intestine Tx are incorporated into routine clinical care worldwide, and both patient and allograft survival are continuing to improve [1]. However, the growing disparity between organ supply and demand has led to the increasing use of donation after circulatory death (DCD) and extended criteria donor (ECD; aged $\geq 60$ years or aged 50-59 years with vascular comorbidities) allografts [2-4], despite their higher susceptibility to ischemia-reperfusion injury (IRI) and consecutive inferior outcomes, including mortality and morbidity after $\mathrm{Tx}[5,6]$.

The organ preservation process is a critical link in the chain of donation and Tx, and therefore is of major interest in research in order to provide strategies to improve Tx outcome [7]. The allograft, metabolically impaired during warm and cold ischemia (WI and CI), is further damaged by a paradox reperfusion injury after revascularization and re-oxygenation. Short-term and long-term complications including post-reperfusion syndrome, delayed graft function (DGF) and even immune activation have been associated with IRI $[5,8]$.

The implementation of new storage techniques, such as machine perfusion (MP), has paved the way for the continuous supply of oxygen and substrates for the synthesis of adenosine triphosphate 
(ATP) and other metabolites, enabling the continuous removal of end products and stimulation of the organ's metabolism [9]. Studies have demonstrated reduced rates of DGF and improved allograft survival in machine-perfused organs compared to static cold storage (SCS) [4,10-12]. Moreover, MP provides a unique opportunity to collect graft tissue and perfusate samples, as well as information regarding functional activity and flow dynamics prior to Tx. The accurate evaluation of allograft quality is essential in order to prevent unjustified donor organ rejection [13,14], and to estimate Tx outcomes. Additionally, MP offers a unique platform to facilitate intervention and modification to further optimize ECD grafts [5,15]. However, it remains unclear which temperature setting is preferable for optimal organ preservation [16]. Hypothermia slows metabolism and oxygen consumption, so that organs can survive longer without nutrient supplements, while normothermia preserves the graft at a near-physiological condition [5].

Metabolomics, firstly introduced in the late 1990s, is a postgenomic high-throughput systems biology approach of diagnostic innovation in clinical medicine $[17,18]$. In metabolomics, a large number of metabolites (sugars, amino acids, lipids, organic acids and nucleotides) can be measured using non-chemical, non-colorimetric methods, such as gas chromatography-mass spectrometry (GC-MS), liquid chromatography-MS (LC-MS) or nuclear magnetic resonance (NMR) spectroscopy [18,19]. The advantages of these analytical approaches are their accuracy, rapidity, the small sample volume, and the possibility of simultaneous detection and quantification in a single measurement, mostly without any preselection [20]. NMR spectroscopy relies on the signals from various nuclei, including ${ }^{1} \mathrm{H}$, ${ }^{31} \mathrm{P}$ and ${ }^{13} \mathrm{C}$, while MS involves the ionization of metabolites present in samples and separation based on the mass/charge ratio [21,22]. Moreover, MS can also be combined with chromatographic methods (LC or GS) to improve metabolite separation. These technologies allow the investigation of metabolic changes in disease models and organ physiology, including Tx [23].

In general, metabolomic approaches have been performed to monitor two key aspects of organ physiology during preservation: (i) severity of organ IRI and (ii) organ function or dysfunction [19]. Several metabolomics studies revealed altered levels of metabolites originating from the urea cycle (urea and glutamate), energy metabolism (e.g., formate, orthophosphate, ATP, lactate, pyruvate, fatty acids and carbohydrates), oxidative phosphorylation (fumarate and succinate) and oxidative stress (increased levels of reduced glutathione) in IRI [19,22].

With a better understanding of the underlying harmful metabolic processes occurring during organ preservation, the possibility of ameliorating organ quality, as well as extending storage time and even improving allograft quality prior to $\mathrm{Tx}$, may become clinical routine. It seems that innovative techniques, such as MP, combined with metabolomics has significant potential as a clinical tool for the assessment of preserved organs before $\mathrm{Tx}$, since many potential biomarkers could be identified with the evolution of metabolomics. However, the current level of evidence is scarce and further studies are needed to pave the way for clinical trials. The purpose of this comprehensive review is to give an overview of the literature on the use of metabolomics in solid organ Tx, with special focus on metabolic profiling during graft preservation in order to compare preservation methods and assess the quality of grafts prior to Tx.

\section{Materials and Methods}

This comprehensive literature review was performed by selecting articles investigating different solid organ preservation methods for Tx, in which analytical techniques of metabolomics were applied. A literature search was conducted in the MEDLINE and EMBASE databases using Medical Subject Heading (MeSH) terms "metabolomics", "heart", "lung", "kidney", "liver", "intestine", "pancreas", and "transplantation" until and including 10 May 2020 (English articles only). All hits were screened by title and abstract by two reviewers (MK and VZ) independently. Then full-text articles were reviewed for potential eligibility. Additional articles identified through reference list screening were included. Database-specific search strategies and a flowchart of the literature search according to the PRISMA 
guideline are provided as Supplementary Materials [24]. In total, 38 publications were included in this study.

\section{Comprehensive Review}

\subsection{Metabolomics in Heart Preservation}

The shortage of donor hearts relative to the demand is an ongoing challenge, given the increasing societal burden of heart failure [25]. A large number of potential donor hearts are discarded because the short safe preservation time of $4-6 \mathrm{~h}$ is exceeded due to logistical reasons $[26,27]$. The standard SCS method is simple and cheap, but suboptimal for preserving cardiac allografts, especially in the case of ECD hearts [26]. Research is currently focusing on the development of new preservation strategies to enhance the preservation of donor hearts, extend the maximum preservation duration, and evaluate the quality of donor hearts prior to Tx [27]. MP provides a continuous perfusion with oxygenated blood or preservation solution, resulting in improved metabolism compared to SCS (Table 1).

Table 1. Metabolomics in heart preservation for Tx.

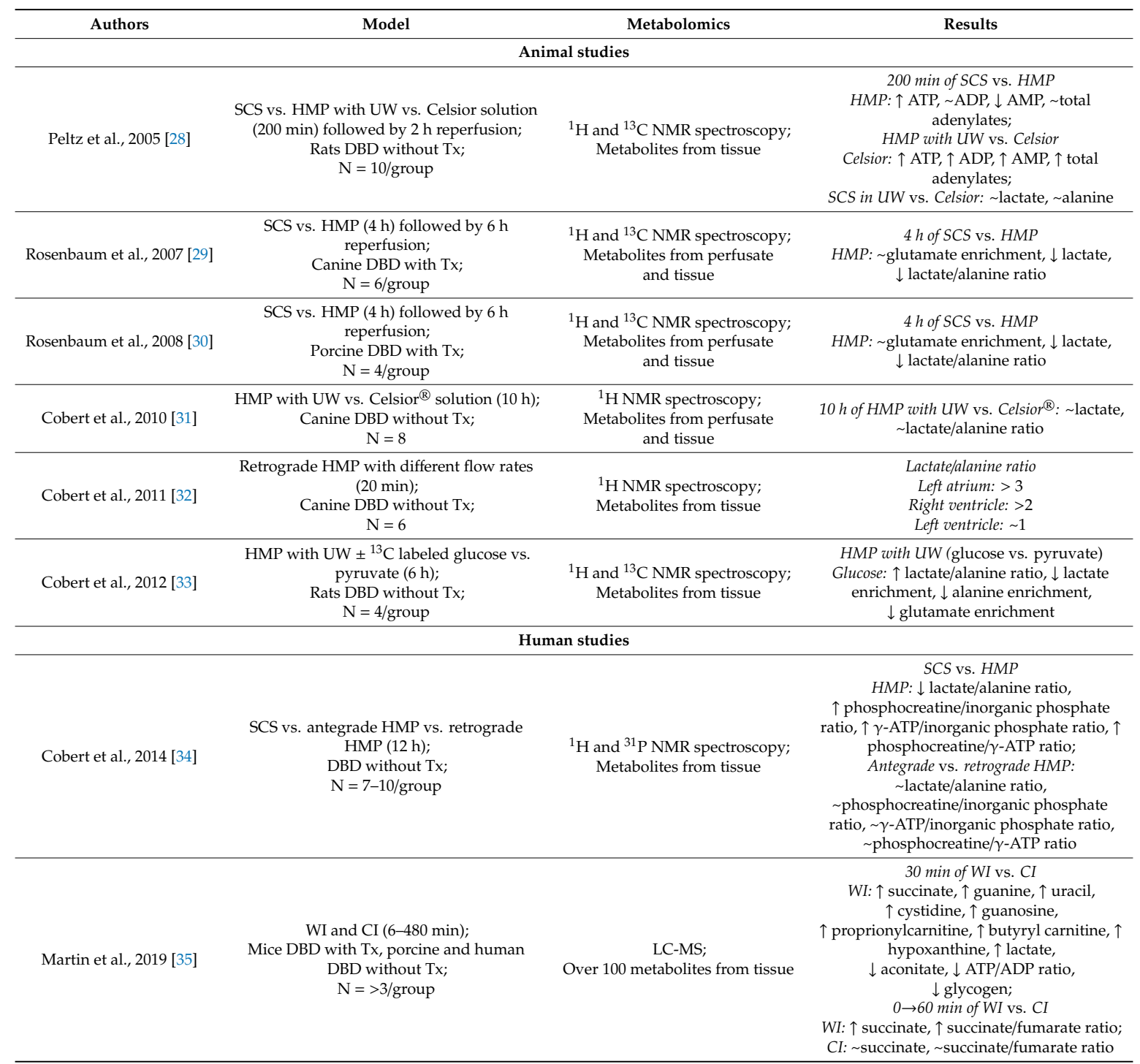

ADP, adenosine diphosphate; AMP, adenosine monophosphate; ATP, adenosine triphosphate; CI, cold ischemia; DBD, donation after brain death; HMP, hypothermic machine perfusion; LC-MS, liquid chromatography-mass spectrometry; NMR, nuclear magnetic resonance; SCS, static cold storage; Tx, transplantation; UW, University of Wisconsin solution; WI, warm ischemia. 
Previous experiments by Peltz et al. suggested significant advantages in rat hearts preserved by hypothermic MP (HMP; $4-10^{\circ} \mathrm{C}$ ) over SCS [28] due to improved cellular ATP and energy charge levels during the ischemic period [28]. In a canine study, NMR spectroscopy analysis revealed a dramatic decrease in tissue lactate in hearts preserved with continuous HMP with similar levels of myocardial edema [29]. After SCS, a more than five-fold increased lactate to alanine ratio was observed when compared to preservation by HMP [29]. Comparable results have been described in large animal experiments performed on pig hearts [30]. Continuous perfusion reduces the functional impairment of myocardium and tissue lactate accumulation without increasing edema; it therefore appears to be a promising tool to improve the results of heart Tx.

In 2010, Cobert et al. compared oxidative metabolism during $10 \mathrm{~h}$ of canine heart HMP with two commonly used extracellular-type preservation solutions (UW and Celsior ${ }^{\circledR}$ ) [31]. Despite increased edema development, no detriment to the metabolic profile, analyzed by ${ }^{1} \mathrm{H}$ NMR spectroscopy of tissue samples, was observed in the Celsior ${ }^{\circledR}$ group. Lactate/alanine ratios remained low in both groups, denoting favorable metabolic profiles in HMP and indicating primarily aerobic metabolism. Moreover, lactate accumulation in the preservation solution was low and did not increase over time in either group [31,32]. Elevated lactate/alanine ratios in the right ventricle and left atrium stood in contrast to the low ratios found in the left ventricle. This data suggested that, despite excellent left ventricular perfusion, right ventricle perfusion is reduced, and oxidative metabolism may not be maintained by retrograde HMP [32].

A previously published study investigated myocardial metabolism on isolated rat hearts during HMP [33]. The authors found that glucose, even if provided at high concentrations, is minimally effective on oxidative pathways during MP. Pyruvate appears to be a more promising exogenous substrate, as the significantly increased incorporation of labeled carbon into Krebs cycle intermediates, in positions that exclusively occur through oxidative metabolism, could be demonstrated via a ${ }^{1} \mathrm{H}$ and ${ }^{13} \mathrm{C}$ NMR spectroscopy approach [33]. Experiments with discarded human hearts showed that HMP could support myocardial metabolism over long periods [34]. The lactate/alanine ratios determined by ${ }^{1} \mathrm{H}$ NMR spectroscopy were lower in all perfused hearts when compared to the SCS group, indicating ongoing oxidative metabolism and reduced intracellular lactate accumulation in the MP groups. Moreover, ${ }^{31} \mathrm{P}$ NMR spectroscopy demonstrated more stable high-energy phosphate to inorganic phosphate ratios in the perfusion groups, indicating that HMP preservation is effective in maintaining myocardial high-energy phosphates even over $12 \mathrm{~h}$ of perfusion [34]. This study demonstrated that the acceptable ischemic interval of donor hearts could be increased using MP techniques; therefore, improved donor-recipient matching and extension of the donor pool could be achieved by permitting for long-distance procurements.

Recently, Martin et al. compared the metabolic changes during WI and CI in mice, as well as in porcine and human hearts using LC-MS [35]. They proposed that succinate accumulation is a major feature within ischemic hearts across species, and that CI slows succinate generation, thereby reducing tissue damage upon reperfusion caused by the production of mitochondrial reactive oxygen species (ROS). Importantly, the inevitable periods of WI during organ procurement lead to the accumulation of damaging levels of succinate, despite cooling organs as rapidly as possible [35]. Moreover, the metabolism during WI and CI was similar in hearts of different species, encouraging the development of therapies using animal models. The data suggest that preventing oxidation and the accumulation of succinate during Tx might improve the outcomes of Tx. This could pave the way towards new treatment approaches.

However, there is a lack of clinical data, and more trials are needed in order to evaluate the role of metabolomics and the possibility of ameliorating graft quality prior to heart Tx.

\subsection{Metabolomics in Lung Preservation}

The field of lung Tx has made significant advances over the last decades. Despite these advances, morbidity and mortality remain high when compared to other examples solid organ Tx [36]. Ex vivo lung 
perfusion is already well established in clinical routine, and allows explanted donor lungs to be perfused and ventilated while being evaluated and reconditioned prior to Tx [36,37]. Advanced knowledge about the metabolic profile during preservation can help in finding innovative biomarkers for early allograft dysfunction (EAD), enabling timely therapeutic intervention to prevent functional decline. Currently, there is only a limited number of available metabolomics studies in lung preservation for $\mathrm{Tx}$ (Table 2).

Table 2. Metabolomics in lung preservation for Tx.

\begin{tabular}{|c|c|c|c|}
\hline Authors & Model & Metabolomics & Results \\
\hline \multicolumn{4}{|c|}{ Animal studies } \\
\hline Pillai et al., 1986 [38] & $\begin{array}{l}\text { NMP with oxygenated blood }(4 \mathrm{~h}) \\
\text { Porcine DBD without Tx; } \\
\text { N = n.d. }\end{array}$ & $\begin{array}{l}{ }^{31} \mathrm{P} \text { NMR spectroscopy, } \\
\text { Metabolites from tissue }\end{array}$ & $\begin{array}{c}\text { During NMP: } \sim \text { ATP, } \sim \text { phosphodiester, } \\
\text { inorganic phosphate, } \\
\sim \text { phosphomonoester; } \\
\text { During anoxia or ischemia: } \downarrow \text { ATP, } \\
\quad \uparrow \text { inorganic phosphate }\end{array}$ \\
\hline Peltz et al., $2005[40,41]$ & $\begin{array}{l}\text { SCS in Perfadex }{ }^{\circledR} \text { with }{ }^{13} \mathrm{C} \text { labeled } \\
\text { glucose vs. pyruvate }(6 \text { and } 24 \mathrm{~h}) ; \\
\text { Rats DBD without Tx; } \\
\mathrm{N}=4-6 / \text { group }\end{array}$ & $\begin{array}{l}{ }^{13} \text { C NMR spectroscopy; } \\
\text { Metabolites from tissue }\end{array}$ & $\begin{array}{l}\text { SCS in Perfadex }{ }^{\circledR} \text { with glucose vs. pyruvate } \\
\text { Pyruvate: } \uparrow \text { glutamate enrichment }\end{array}$ \\
\hline \multicolumn{4}{|c|}{ Human studies } \\
\hline Hsin et al., 2018 [43] & $\begin{array}{l}\text { NMP }(1 \mathrm{~h} \text { and } 4 \mathrm{~h}) ; \\
\text { Marginal grafts with } \mathrm{Tx} \\
\quad \mathrm{N}=50\end{array}$ & $\begin{array}{l}\text { Mass spectrometry; } \\
275 \text { metabolites } \\
\text { from perfusate }\end{array}$ & $\begin{array}{c}P G D \text { after } 1 \text { h of NMP: } \\
\uparrow \text { palmitoyl-sphingomyelin, } \\
\uparrow 5 \text {-aminovalerate, } \\
\uparrow \text { decanoylcarnitine; } \\
P G D \text { after } 4 \text { h of NMP: } \\
\uparrow \text { N2-methylguanosine, } \uparrow \\
\text { 5-aminovalerate, } \uparrow \text { oleamide, } \\
\uparrow \text { decanoylcarnitine }\end{array}$ \\
\hline
\end{tabular}

DCD, donation after circulatory death; EC, Euro-Collins solution; HMP, hypothermic machine perfusion; NMP, normothermic machine perfusion; NMR, nuclear magnetic resonance; PGD, primary graft dysfunction; PEG, polyethylene glycol solution; SCS, static cold storage; Tx, transplantation.

Pillai et al. showed, as early as 1986, the feasibility of obtaining ${ }^{31} \mathrm{P}$ NMR spectra of porcine lungs maintained in a viable state during normothermic MP $\left(\mathrm{NMP} ; 37^{\circ} \mathrm{C}\right)$ with oxygenated blood [38]. During anoxia or ischemia, ATP and intracellular $\mathrm{pH}$ declined and inorganic phosphate increased, but all returned to control levels during subsequent normoxia or reperfusion [38]. Deep knowledge on the recovery of the lungs from anoxia and ischemia is important in order to improve the protocols for preservation.

In 2003, Jayle et al. presented the beneficial effects of polyethylene glycol (PEG) in lung cold preservation [39]. In their study, PEG preserved porcine lungs better than UW and Euro-Collins (EC) solution. By means of ${ }^{1} \mathrm{H}$ NMR spectroscopy, lactate, pyruvate, citrate and acetate were only detected after reperfusion, with a reduced production of acetate and pyruvate in PEG-preserved organs indicating a better mitochondria metabolism and integrity [39]. As a result, PEG solution was able to improve the pulmonary vascular resistance and reduce leukocyte infiltration (the important factors related to IRI).

Peltz et al. characterized lung metabolism in rats by ${ }^{13} \mathrm{C}$ NMR spectroscopy, and suggested that glucose added to lung preservation solutions plays a minor role as an energy source [40,41]. Instead, the lung prefers to catabolize endogenous fuels during the SCS period. Adding a substrate such as pyruvate leads to multiple metabolic alterations, including the following: (i) enhanced overall oxidative metabolism, (ii) reduction of the contribution of endogenous stores, and (iii) activation of glucose 
and glycogen synthesis [40]. To sum up, the addition of pyruvate to Perfadex ${ }^{\circledR}$ solution increased metabolism during SCS and improved lung function after reperfusion [40,41]. The development of metabolomic techniques allowed the exploration of the preservation solution substrate's composition's influence on graft metabolism during storage. Further research could help to extend the ischemic interval of stored lungs and improve the results of lung Tx.

In 2012, Benahmed et al. assessed the tissue quality of DCD pigs' lungs using ${ }^{1} \mathrm{H}$ NMR spectroscopy [42]. They identified 35 mostly upregulated metabolites over the period of SCS, indicating cellular degradation, whereas levels of glutathione decreased. During HMP, the majority of the metabolites remained stable, including glutathione. In contrast, the levels of uracil showed a reverse profile, indicating cell damage followed by oxidative stress. These results demonstrated that HMP has a positive effect on lung quality by protecting cells against oxidative disorders. Moreover, glutathione and uracil were found to be promising biomarkers for the evaluation of lung quality prior to Tx [42]. The authors described NMR to be a very reliable and rapid technique, which can be simply implemented in a hospital environment.

More recently, Hsin et al. revealed a small panel of metabolites, such as N2-methylguanosine, 5 -aminovalerate, oleamide and decanoylcarnitine, in the perfusate highly correlating with primary graft dysfunction (PGD). These metabolites were identified as potential biomarkers for the selection of human ECD lungs after $4 \mathrm{~h}$ of ex vivo lung NMP [43]. However, further validation studies are needed to confirm these findings. By identifying high risk lung grafts, it may be possible to develop ex vivo repair strategies, using the MP platform, to render these lungs suitable for Tx.

\subsection{Metabolomics in Kidney Preservation}

Kidney Tx indisputably confers a significant survival advantage and a better quality of life compared to dialysis [44]. Currently, there is increasing evidence supporting the use of pulsatile MP over SCS in kidney preservation [4], but more studies are needed to compare MP and SCS. Previous studies suggested that metabolomics might be a useful method of evaluating renal medullary damage ex vivo after $\mathrm{CI}$ and reperfusion from tissue, plasma, urine and perfusate samples, showing more efficient results than conventional histology and biochemical analysis (Table 3).

Table 3. Metabolomics in kidney preservation for Tx.

\begin{tabular}{|c|c|c|c|}
\hline Authors & Model & Metabolomics & Results \\
\hline \multicolumn{4}{|c|}{ Animal studies } \\
\hline Richer et al., 2000 [45] & $\begin{array}{l}\text { SCS in UW vs. EC }(48 \mathrm{~h}) \\
\text { Porcine } \mathrm{DBD} \text { with autoTx; } \\
\quad \mathrm{N}=7 / \text { group }\end{array}$ & $\begin{array}{l}{ }^{1} \mathrm{H} \text { NMR spectroscopy; } \\
\text { Metabolites from plasma } \\
\text { and urine }\end{array}$ & $\begin{array}{c}\text { SCS in UW vs. EC after reperfusion } \\
\text { UW in urine: } \downarrow \text { trimethylamidoxide/creatinine ratio, } \\
\downarrow \text { dimethylamine/creatinine ratio; } \\
\text { UW in plasma: } \downarrow \text { trimethylamidoxide }\end{array}$ \\
\hline Hauet et al., 2000 [20] & $\begin{array}{l}\text { SCS in UW vs. EC }(48 \mathrm{~h}) \\
\text { Porcine DBD with autoTx; } \\
\quad \mathrm{N}=14 / \text { group }\end{array}$ & $\begin{array}{l}{ }^{1} \mathrm{H} \text { NMR spectroscopy; } \\
\text { Metabolites from plasma } \\
\text { and urine }\end{array}$ & $\begin{array}{c}\text { SCS in UW vs. EC after reperfusion } \\
U W: \downarrow \text { dimethylamine/creatinine ratio, } \\
\downarrow \text { trimethylamidoxide/creatinine ratio, } \\
\uparrow \text { citrate/creatinine ratio, } \downarrow \text { acetate/creatinine ratio, } \\
\downarrow \text { lactate/creatinine ratio }\end{array}$ \\
\hline Hauet et al., 2000 [46] & $\begin{array}{l}\text { SCS in UW vs. EC }(24 \mathrm{~h}) \text { followed } \\
\text { by } 90 \text { min reperfusion; } \\
\text { Porcine DBD, single vs. multiorgan } \\
\text { donor without Tx; } \\
\quad \mathrm{N}=10 \text { /group }\end{array}$ & $\begin{array}{l}{ }^{1} \mathrm{H} \text { NMR spectroscopy; } \\
\text { Metabolites from urine }\end{array}$ & $\begin{array}{c}\text { SCS in } U W \text { vs. EC after reperfusion } \\
\text { UW in urine: } \sim \mathrm{N} \text {-acetyl- } \beta \text {-D-glucosaminidase, } \\
\downarrow \text { lactate/creatinine ratio, } \downarrow \text { acetate/creatinine ratio, } \\
\downarrow \text { trimethylamineoxide/creatinine ratio; } \\
\text { Single vs. multiorgan donor } \\
\text { Single organ in urine: } \downarrow \text { lactate/creatinine ratio, } \\
\downarrow \text { acetate/creatinine ratio, } \\
\downarrow \text { trimethylamineoxide/creatinine ratio, } \\
\uparrow \text { amino acid, } \uparrow \text { citrate }\end{array}$ \\
\hline Serkova et al., 2005 [47] & $\begin{array}{l}\text { SCS }(24 \text { vs. } 42 \text { h) } \pm \mathrm{Tx} \\
\text { Rats DBD with Tx; } \\
\mathrm{N}=>6-8 / \text { group }\end{array}$ & $\begin{array}{l}{ }^{1} \mathrm{H} \text { NMR spectroscopy; } \\
\text { Over } 50 \text { metabolites from } \\
\text { plasma and tissue }\end{array}$ & $\begin{array}{c}24 \text { vs. } 42 \text { h of SCS after reperfusion } \\
24 \mathrm{~h} \text { in blood: } \sim \text { creatinine, } \downarrow \text { allantoin, } \\
\uparrow \text { polyunsaturated fatty acids; } \\
24 h \text { in tissue: } \downarrow \text { allantoin, } \\
\downarrow \text { trimethylamidoxide }\end{array}$ \\
\hline
\end{tabular}


Table 3. Cont.

\begin{tabular}{|c|c|c|c|}
\hline Authors & Model & Metabolomics & Results \\
\hline \multicolumn{4}{|c|}{ Animal studies } \\
\hline Buchs et al., 2011 [48] & $\begin{array}{l}\text { HOPE vs. SCS }(8 \text { and } 18 \mathrm{~h}) \\
\text { Porcine DCD vs. DBD without Tx; } \\
\text { N }=7\end{array}$ & $\begin{array}{l}{ }^{31} \text { P NMR spectroscopy; } \\
\text { Metabolites from n.d. }\end{array}$ & $\begin{array}{c}8 \rightarrow 18 \text { h of HOPE }(D B D): \sim \text { phosphomonoester, } \\
\sim \gamma \text {-ATP, } \sim \alpha \text {-ATP, } \\
\sim \beta \text {-ATP; } \\
8 \rightarrow 18 \text { h of HOPE }(D C D): \\
\uparrow \text { phosphomonoester, } \downarrow \beta \text {-ATP; } \\
8 \text { h of SCS } \rightarrow 8 \text { h of HOPE }(D B D): \\
\downarrow \text { phosphomonoester } \uparrow \uparrow \text {-ATP, } \uparrow \alpha \text {-ATP, } \\
\uparrow \beta \text {-ATP; } \uparrow \text { NADH; } \\
18 h \text { of SCS } \rightarrow 8 \text { h of HOPE }(D B D): \\
\downarrow \text { phosphomonoester, } \uparrow \gamma \text {-ATP, } \uparrow \alpha \text {-ATP, } \\
\downarrow \text { NADH }\end{array}$ \\
\hline Bon et al., 2014 [49] & $\begin{array}{l}\text { HMP }(22 \mathrm{~h}) \\
\text { Porcine DCD with autoTx; } \\
\text { N }=10\end{array}$ & $\begin{array}{l}\text { NMR spectroscopy; } \\
\text { Metabolites from } \\
\text { perfusate }\end{array}$ & $\begin{array}{c}\text { Inferior outcomes: } \uparrow \text { lactate, } \uparrow \text { choline, } \\
\uparrow \text { amino acids (valine, glycine and glutamate), } \\
\downarrow \text { glutathione }\end{array}$ \\
\hline Nath et al., 2016 [50] & $\begin{array}{l}\text { HMP }(6 \text { and } 24 \mathrm{~h}) \\
\text { Porcine DBD without Tx; } \\
\text { N }=6\end{array}$ & $\begin{array}{l}{ }^{1} \mathrm{H} \text { and }{ }^{13} \mathrm{C} \mathrm{NMR} \\
\text { spectroscopy; } \\
\text { Metabolites from } \\
\text { perfusate and tissue }\end{array}$ & $6 \rightarrow 24$ h of HMP: $\uparrow$ lactate, $\uparrow$ alanine, $\sim$ acetate \\
\hline Nath et al., 2017 [11] & $\begin{array}{l}\text { HMP vs. SCS }(24 \mathrm{~h}) \\
\text { Porcine DCD without Tx; } \\
\text { N }=20\end{array}$ & $\begin{array}{l}{ }^{1} \mathrm{H} \text { NMR spectroscopy; } \\
26 \text { metabolites from } \\
\text { storage fluid/perfusate } \\
\text { and tissue }\end{array}$ & $\begin{array}{c}H M P \text { vs. } S C S \\
H M P: \uparrow \text { glutamate, } \uparrow \text { myoinositol, } \uparrow \text { lactate, } \\
\uparrow \text { formate, } \uparrow \text { acetate, } \uparrow \text { inosine, } \uparrow \text { aspartate, } \\
\uparrow \text { niacinamide, } \uparrow \text { fumarate }\end{array}$ \\
\hline Patel et al., 2019 [51] & $\begin{array}{l}\text { HOPE vs. aerated HMP }(18 \mathrm{~h}) \\
\text { Porcine DCD without } \mathrm{Tx} \\
\mathrm{N}=16\end{array}$ & $\begin{array}{l}{ }^{13} \text { C NMR spectroscopy } \\
\text { and GC-MS; } \\
\text { Metabolites from } \\
\text { perfusate and tissue }\end{array}$ & $\begin{array}{c}\text { HOPE vs. aerated HMP } \\
\text { HOPE: } \downarrow \text { lactate, } \uparrow \text { glutamate, } \uparrow \text { ATP, } \\
\downarrow \text { alanine, } \sim \text { citrate, } \uparrow \text { succinate, } \sim \text { malate }\end{array}$ \\
\hline Darius et al., 2020 [52] & $\begin{array}{c}\text { HMP } \pm 30 \% \text { vs. } 90 \% \text { oxygen }(22 \mathrm{~h}) \\
\text { Porcine DCD with autoTx } \\
\mathrm{N}=28\end{array}$ & $\begin{array}{l}{ }^{1} \mathrm{H} \text { NMR spectroscopy; } \\
16 \text { metabolites from } \\
\text { perfusate }\end{array}$ & $\begin{array}{c}\text { HMP } \pm 30 \% \text { vs. } 90 \% \text { oxygen } \\
\text { HMP }+90 \% \text { oxygen: } \downarrow \text { acetate, } \sim \text { adenine, } \\
\uparrow \text { alanine, } \uparrow \text { aspartate, } \downarrow \text { formate, } \\
\downarrow \text { gluconate, } \downarrow \text { glutamate, } \uparrow \text { glutathione, } \\
\downarrow \text { glycine, } \downarrow \text { hypoxanthine, } \sim \text { isoleucine, } \\
\downarrow \text { lactate, } \sim \text { leucine, } \downarrow \text { mannitol, } \downarrow \text { myo-inositol, } \\
\downarrow \text { succinate }\end{array}$ \\
\hline \multicolumn{4}{|c|}{ Human studies } \\
\hline Nath et al., 2014 [53] & $\begin{array}{l}\text { HMP }(45 \min \text { and } 4 \mathrm{~h}) \text {; } \\
\text { Human vs. porcine DBD without Tx; } \\
\qquad \mathrm{N}=22\end{array}$ & $\begin{array}{l}{ }^{1} \mathrm{H} \text { NMR spectroscopy; } \\
30 \text { metabolites from } \\
\text { perfusate }\end{array}$ & $\begin{array}{c}\text { Human vs. porcine grafts Human: } \sim \text { conc. of } 53.3 \% \\
\text { metabolites, } \sim \text { change rate of conc. of } 96.7 \% \\
\text { metabolites, } \uparrow \text { change rate of conc. for } \\
\text { 3-hydroxybutyrate }\end{array}$ \\
\hline Guy et al., 2015 [10] & $\begin{array}{l}\text { HMP (45 min and } 4 \mathrm{~h}) \\
\text { DBD and DCD with Tx; } \\
\qquad \mathrm{N}=26\end{array}$ & $\begin{array}{l}{ }^{1} \mathrm{H} \text { NMR spectroscopy; } \\
28 \text { metabolites from } \\
\text { perfusate }\end{array}$ & $\begin{array}{c}D G F \text { vs. IGF } \\
D G F: \downarrow \text { glucose, } \downarrow \text { inosine, } \uparrow \text { leucine, } \\
\downarrow \text { gluconate; } \\
\text { IGF: } \uparrow \text { glucose, } \uparrow \text { inosine, } \downarrow \text { leucine, } \\
\uparrow \text { gluconate }\end{array}$ \\
\hline
\end{tabular}

ATP, adenosine triphosphate; DBD, donation after brain death; DCD, donation after circulatory death; DGF, delayed graft function; EC, Euro-Collins solution; GC-MS, gas chromatography-mass spectrometry; HMP, hypothermic machine perfusion; HOPE, hypothermic oxygenated machine perfusion; IGF, immediate graft function; NADH, nicotinamide adenine dinucleotide; NMR, nuclear magnetic resonance; SCS, static cold storage; Tx, transplantation.

Early experimental studies on porcine kidneys compared two standard preservation solutions, UW and EC, for kidney SCS (24 and $48 \mathrm{~h})[20,45,46]$. The most relevant metabolites for evaluating kidney function after autoTx, determined by ${ }^{1} \mathrm{H}$ NMR spectroscopy, were citrate, dimethylamine (DMA), lactate and acetate in urine, and trimethylamine-N-oxide (TMAO) in urine and plasma. While the $\mathrm{TMAO} /$ creatinine, DMA/creatinine, lactate/creatinine and acetate/creatinine ratios were significantly higher in kidneys stored in EC solution compared to UW solution [20], the citrate/creatinine ratio was elevated in the UW group compared to the EC group during follow-up. These findings clearly demonstrated that retrieval conditions might influence renal medulla injury, and that UW solution is more efficient in reducing renal medullary damage than EC solution, even after prolonged CI $[20,45,46]$. Moreover, NMR spectroscopy was able to discriminate kidneys with significant renal damage more efficiently than conventional biochemical parameters and light microscopy [46].

Previously, ${ }^{1} \mathrm{H}$ NMR-based metabolic profiling revealed mild and severe IRI in rat kidney grafts after 24 and $42 \mathrm{~h}$ of SCS, respectively [47]. Significantly decreased levels of polyunsaturated fatty acids and elevated levels of allantoin, a marker of oxidative stress, were found after $42 \mathrm{~h}$ of SCS. TMAO, a marker of renal medullary injury, and allantoin were significantly increased, correlating with the 
severity of histologic damage, while serum creatine (commonly used end point) values were not different between Tx groups [47]. In future clinical applications, quantitative metabolomics may help to distinguish between IRI, and early and chronic rejection.

In 2014, Bon et al. proposed a protocol for MP perfusate metabolomics analysis as a tool for the assessment of preserved kidney quality, to reduce the number of discarded organs and optimize patient management [49]. The potential of NMR to predict graft outcome by analyzing perfusates in a DCD pig model of kidney autoTx, over $22 \mathrm{~h}$ of HMP, was evaluated. Levels of several metabolites, including lactate, choline, or amino acids such as valine, glycine or glutamate, increased over time, whereas there was a reduction in total glutathione during this period. The changes in these biomarkers were less severe in grafts with better function recovery based on lower plasma creatinine levels determined after 3 months [49]. The authors concluded that the analysis of biomarkers during kidney HMP using NMR could be an interesting tool for assessing graft quality, and was compatible with clinical application.

Another study characterized the metabolic profile of porcine DCD kidneys using ${ }^{1} \mathrm{H}$ NMR spectroscopy over $24 \mathrm{~h}$ of HMP, compared to traditional SCS controls [11]. The total amount of central metabolites, such as lactate, glutamate, fumarate, aspartate and acetate, observed in the HMP kidney system suggests a greater degree of de novo metabolic activity than during SCS [11]. Whilst the majority of glucose is metabolized into glycolytic endpoint metabolites, such as lactate, the presence of non-glycolytic pathway derivatives suggests that the metabolism during HMP is more complex than previously thought [50]. The maintenance of central metabolic pathways may contribute to the clinical benefits of HMP.

Supplemental oxygenation during HMP was proposed to restore cellular ATP levels and ensure metabolic activity in DCD kidney grafts [48]. More recently, using NMR combined with GC-MS, Patel et al. found that $18 \mathrm{~h}$ HMP of porcine DCD kidneys with high perfusate partial pressure of oxygen $\left(\mathrm{PO}_{2}, 95 \%\right)$ results in a greater degree of aerobic metabolism at the end of MP, compared to active aeration (21\%) [51]. Darius et al. [52] investigated the metabolic, functional, structural and flow dynamic effects of low and high perfusate $\mathrm{PO}_{2}(30 \%$ vs. $90 \%)$ during a continuous $22 \mathrm{~h}$ HMP in a porcine DCD kidney IRI autoTx model, confirming those findings. ${ }^{1} \mathrm{H}$ NMR analysis was used to determine the concentration of metabolites within the circulating perfusate at the end of the perfusion. While this animal study did not yield any advantages for early graft function after high perfusate $\mathrm{PO}_{2}$, compared to low $\mathrm{PO}_{2}$, perfusate metabolic profile analysis suggested that high perfusate $\mathrm{PO}_{2}$ conditions supported the aerobic mechanism [52]. More effective MP strategies could reduce the harmful effects of IRI, hence improving outcomes of Tx.

Subsequently, NMR spectroscopy was used to examine the metabolic profile of the HMP perfusate, at $45 \mathrm{~min}$ and $4 \mathrm{~h}$, from human cadaveric kidneys awaiting Tx [10]. In this study, promising discriminators between kidneys with DGF and those with immediate graft function (IGF) were identified. Glucose, inosine and gluconate concentrations were lower in DGF kidneys compared to IGF at both time points, while leucine concentrations were higher [10]. During kidney HMP, a significant portion of the metabolic activity persists-a currently poorly understood mechanism. Therefore, further research on the modification of harmful metabolic processes may improve graft-related outcomes, and consequently has the potential to modify ECD organs. Furthermore, it remains unclear how accurately levels of perfusate metabolites reflect intracellular activity.

The same research group later compared the metabolic profiles of human and porcine kidneys with regard to HMP-derived perfusate to determine whether the porcine model is a valid surrogate for human studies [53]. Out of 30 metabolites analyzed, 16 were present in comparable concentrations in the pig and human kidney perfusates. Only 3-hydroxybutyrate showed significantly different rates of concentration change [53]. It seems that pig and human kidneys during HMP appear to be metabolically similar, confirming the pig as a valuable model for further kidney-related studies. 


\subsection{Metabolomics in Liver Preservation}

Rapidly increasing demands for liver Tx have caused severe shortages of donor liver organs [12]. Data on different preservation strategies suggest that MP is superior to SCS in improving short-term outcomes after human liver Tx, with a less clear effect in the longer term [12]. The use of metabolomics during liver preservation shows promising results in developing objective and reliable techniques to metabolically profile liver grafts and find reliable prognostic biomarkers prior to Tx (Table 4).

Table 4. Metabolomics in liver preservation for Tx.

\begin{tabular}{|c|c|c|c|}
\hline Authors & Model & Metabolomics & Results \\
\hline \multicolumn{4}{|c|}{ Animal studies } \\
\hline Busza et al., 1994 [54] & $\begin{array}{l}\text { SCS }(48 \mathrm{~h}) \text { in plasma-like vs. } \\
\text { modified UW followed by } 1 \mathrm{~h} \text { HMP; } \\
\text { Rats DBD without Tx; } \\
\qquad \mathrm{N}=10\end{array}$ & $\begin{array}{l}{ }^{31} \text { P NMR spectroscopy; } \\
\text { Metabolites from } \\
\text { whole organ }\end{array}$ & $\begin{array}{c}\text { After } 48 \text { h of SCS: } \downarrow \text { ATP, } \downarrow \text { ADP, } \\
\uparrow \text { inorganic phosphate; } \\
\text { Plasma-like vs. modified UW solution (after reperfusion) } \\
\text { Modified UW: } \uparrow \beta \text {-ATP/NAD(H) ratio, } \\
\downarrow \text { inorganic phosphate }\end{array}$ \\
\hline Gibelin et al., 2000 [57] & $\begin{array}{l}\text { SCS in EC vs. UW solution }(24 \mathrm{~h}) \\
\text { followed by } 90 \text { min reperfusion; } \\
\text { Rat DBD without Tx; } \\
\qquad \mathrm{N}=10\end{array}$ & $\begin{array}{l}\text { NMR spectroscopy; } \\
\text { Metabolites from } \\
\text { perfusate }\end{array}$ & $\begin{array}{c}\text { SCS in EC vs. UW } \\
\text { UW: } \uparrow \text { lactates, } \uparrow \text { pyruvate, } \uparrow \text { succinate, } \uparrow \text { citrate, } \\
\uparrow \text { aceto-acetate, } \uparrow \beta \text {-hydroxybutyrate }\end{array}$ \\
\hline Habib et al., 2004 [58] & $\begin{array}{l}\text { SCS (40 min) followed by } 6 \text { h NMP; } \\
\text { Rabbits DBD vs. DCD without Tx; } \\
\qquad \mathrm{N}=4 \text { /group }\end{array}$ & $\begin{array}{l}{ }^{1} \mathrm{H} \text { NMR spectroscopy; } \\
\text { Metabolites from bile }\end{array}$ & $\begin{array}{c}\text { During } 6 h \text { NMP: } \uparrow \text { bile acids, } \uparrow \text { lactate, } \\
\uparrow \text { glucose, } \uparrow \text { phosphatidylcholine, } \downarrow \text { acetate; } \\
D B D \text { vs. DCD } \\
D B D: \downarrow \text { bile acids, } \downarrow \text { lactate, } \downarrow \text { glucose, } \\
\downarrow \text { phosphatidylcholine, } \uparrow \text { acetate }\end{array}$ \\
\hline \multicolumn{4}{|c|}{ Human studies } \\
\hline Lanir et al., 1988 [61] & $\begin{array}{l}\text { SCS }(1.9-6.8 \mathrm{~h}) \\
\text { DBD and DCD with Tx; } \\
\quad \mathrm{N}=25\end{array}$ & $\begin{array}{c}\text { LC-MS; } \\
\text { Metabolites from tissue }\end{array}$ & $\begin{array}{c}\text { Prior to } T x \\
\text { Success: } \uparrow \text { ATP, } \uparrow \text { ADP, } \sim \text { AMP, } \uparrow \text { ATP/ADP ratio, } \\
\uparrow \text { energy change, } \uparrow \text { total adenine nucleotide content, } \\
\uparrow \text { guanosine diphosphate, } \uparrow \text { uridine triphosphate, } \\
\sim \text { hypoxanthine, } \sim \text { xanthine, } \sim \text { NAD + }\end{array}$ \\
\hline Duarte et al., 2005 [62] & $\begin{array}{l}\text { SCS }(9-13 \mathrm{~h}) \\
\text { DBD with Tx; } \\
\quad \mathrm{N}=6\end{array}$ & $\begin{array}{l}{ }^{1} \mathrm{H} \text { NMR spectroscopy; } \\
\text { Metabolites from tissue }\end{array}$ & $\begin{array}{c}\text { Before retrieval vs. after SCS vs. post Tx } \\
\text { PGF: } \uparrow \text { glycerophosphocholine; } \\
\text { PGD: } \sim \text { glycerophosphocholine; } \\
\text { Steatotic vs. non-steatotic grafts } \\
\text { Steatotic: } \uparrow \text { triglycerides, } \downarrow \text { phospholipids, } \\
\downarrow \text { amino acids, } \downarrow \text { glucose, } \downarrow \text { nucleotide-related } \\
\text { compounds, } \downarrow \text { clearance of UW }\end{array}$ \\
\hline
\end{tabular}


Table 4. Cont.

\begin{tabular}{|c|c|c|c|}
\hline Authors & Model & Metabolomics & Results \\
\hline \multicolumn{4}{|c|}{ Human studies } \\
\hline Bruinsma et al., 2016 [63] & $\begin{array}{c}\text { SNMP }(3 \mathrm{~h}) \\
\text { DCD vs. ECD without Tx; } \\
\mathrm{N}=21\end{array}$ & $\begin{array}{l}\text { LC-MS and GC-MS; } \\
159 \text { metabolites from } \\
\text { perfusate and tissue }\end{array}$ & $\begin{array}{c}0 \text { vs. } 3 h \text { of SNMP: } \downarrow \text { carbohydrates } \\
\text { (glucose- } 6 \text {-phosphate, fructose- } 6 \text {-phosphate, glycerol, } \\
\text { xylitol, ribulose-5-phosphate, N-acetylmannosamine, } \\
\text { maltose, raffinose, glyceric acid), } \uparrow \text { amino acids } \\
\text { (valine, threonine, proline, leucine, isoleucine and } \\
\text { glutamine), } \uparrow \text { citric acid, } \\
\uparrow \alpha \text {-ketoglutarate, } \downarrow \text { lactic acid, } \\
\uparrow 2 \text {-hydroxyglutaric acid, } \uparrow \text { urea, } \downarrow \text { uric acid, } \\
\uparrow \text { oxoproline, } \downarrow \text { N-acetyl-D-hexosamine; } \\
0 \rightarrow 3 h \text { of SNMP: } \\
\uparrow \text { amino acids (valine, threonine, leucine and } \\
\text { isoleucin), } \downarrow \text { lactic acid; } \\
D C D \text { vs. ECD } \\
\text { DCD: } \uparrow \text { ATP, } \downarrow \text { oxidized glutathione/glutathione ratio, } \\
\downarrow \text { NADH/NAD ratio }\end{array}$ \\
\hline Karimian et al., 2019 [64] & $\begin{array}{c}\text { SNMP vs. NMP }(3 \mathrm{~h}) \\
\text { DBD/DCD (steatosis }>30 \%) \\
\text { without Tx; } \\
\text { N = } 14\end{array}$ & $\begin{array}{c}\text { LC-MS; } \\
\text { Over } 1600 \text { metabolites } \\
\text { from tissue }\end{array}$ & $\begin{array}{c}\text { After } 3 h \text { of SNMP vs. NMP } \\
\text { SNMP: } \downarrow \text { glutathione, } \downarrow \text { cysteinylglycine, } \\
\uparrow 5 \text {-oxoproline, } \uparrow \text { glutamate, } \downarrow \text { cysteine, } \\
\uparrow \text { glycine, } \downarrow \gamma \text {-glutamylcysteine, } \uparrow \text { citrate, } \\
\downarrow \alpha \text {-ketoglutarate, } \downarrow \text { succinate, } \uparrow \text { fumarate, } \uparrow \text { malate, } \\
\downarrow \text { maltopentaose, } \downarrow \text { maltotriose, } \downarrow \text { maltose }\end{array}$ \\
\hline Raigani et al., 2020 [65] & $\begin{array}{c}\mathrm{NMP}(3 \mathrm{~h}) \\
\text { DBD/DCD (non-steatotic vs. } \\
\text { steatotic) without Tx; } \\
\mathrm{N}=8\end{array}$ & $\begin{array}{c}\text { LC-MS; } \\
\text { Over } 1600 \text { metabolites } \\
\text { from tissue }\end{array}$ & $\begin{array}{c}\text { Non-steatotic vs. steatotic after } 3 \text { h of NMP } \\
\text { Non-steatotic: } \uparrow \text { glutathione, } \downarrow \text { oxidized glutathione, } \\
\uparrow \text { N-acetylcysteine, } \sim \text { ATP/ADP ratio, } \uparrow \text { carnitine, } \\
\downarrow \beta \text {-hydroxybutyrate, } \sim \text { citrate, } \downarrow \alpha \text {-ketoglutarate, } \\
\uparrow \text { succinate, } \uparrow \text { fumarate, } \\
\uparrow \text { malate, } \uparrow \text { glucose- } 6 \text {-phosphate, } \sim \text { dihydroxyacetone } \\
\text { phosphate, } \uparrow 2 \text {-phosphoglycerate, } \\
\uparrow \text { phosphoenolpyruvate, } \uparrow \text { ribulose- } 5 \text {-phosphate, } \\
\uparrow \text { ribose-5-phosphate, } \uparrow \text { xylulose- } 5 \text {-phosphate, } \\
\uparrow \text { eicosapentaenoic acid, } \\
\uparrow \text { docosapentaenoic acid, } \uparrow \text { docosahexaenoic acid, } \\
\uparrow \text { cholesterol, } \sim \text { taurine, } \sim \text { choline }\end{array}$ \\
\hline Xu et al., 2020 [66] & $\begin{array}{l}\text { SCS }(210-840 \mathrm{~min}) ; \\
\text { DBD vs. DCD with Tx; } \\
\quad \mathrm{N}=47\end{array}$ & $\begin{array}{c}\text { LC-MS; } \\
\text { Metabolites from tissue }\end{array}$ & $\begin{array}{c}D B D \text { vs. } D C D \\
D B D: \uparrow \mathrm{AMP} / \text { urate ratio, } \uparrow \text { adenosine/urate ratio, } \\
\uparrow \text { adenine/urate ratio, } \\
\uparrow \text { hypoxanthine/urate ratio; } \\
E G F \text { vs. EAD } \\
E G F: \uparrow \mathrm{AMP} / \text { urate ratio, } \sim \text { adenosine/urate ratio, } \\
\uparrow \text { adenine/urate ratio, } \sim \text { hypoxanthine/urate ratio }\end{array}$ \\
\hline
\end{tabular}

ADP, adenosine diphosphate; AMP, adenosine monophosphate; ATP, adenosine triphosphate; BCAA, branched-chain amino acid; DBD, donation after brain death; DCD, donation after circulatory death; EC, Euro-Collins solution; ECD, extended criteria donor; EAD, early allograft dysfunction; EGF, early graft function; GC-MS, gas chromatography-mass spectrometry; HBOC, hemoglobin-based oxygen carrier; HMP, hypothermic machine perfusion; LC-MS, liquid chromatography-mass spectrometry; NADH, nicotinamide adenine dinucleotide; NMP, normothermic machine perfusion; NMR, nuclear magnetic resonance; PGD, primary graft dysfunction; PGF, primary graft function; SCS, static cold storage; SNMP, subnormothermic machine perfusion; Tx, transplantation; UW, University of Wisconsin solution; WI, warm ischemia time.

Hypothermic resuscitation perfusion of the preserved liver was capable of restoring high-energy nucleotides even after prolonged SCS time (48 h) [54]. The metabolic profiles of adenine nucleotides demonstrated a direct correlation between high ATP content prior to Tx and improved outcome in terms of liver function, as indicated by the normalization of serum enzyme levels and prothrombin time post Tx [61]. In porcine liver grafts, the levels of nucleotide triphosphates decreased to undetectable levels during $4 \mathrm{~h}$ of SCS, but regenerated after $2 \mathrm{~h}$ of oxygenated HMP, while glycolytic intermediates (3-phosphoglycerate and 2,3 diphosphoglycerate) increased significantly during SCS and subsequently declined following HMP [55]. Cellular damage, determined by the concentrations of glycerophosphorylcholine (GPC) and glycerophosphorylethanolamine (GPE), was minimal during SCS. However, upon HMP, the levels of GPC and GPE decreased, indicating a degree of cellular damage caused by reperfusion [55]. Interestingly, prolonged SCS (24 h) was associated with a significantly reduced (approximately 40\%) liver capacity to regenerate ATP levels during hypothermic reperfusion when compared to the shorter SCS time (2 h) [56]. 
Gibelin et al. assessed liver graft function in isolated perfused rat livers after $24 \mathrm{~h}$ of preservation in EC vs. UW solution at $4{ }^{\circ} \mathrm{C}$ [57]. The transaminases levels were similar in these groups; however, the levels of lactate, pyruvate, succinate, citrate, aceto-acetate and b-hydroxybutyrate detected by proton NMR were significantly higher in the UW than in the EC group [57]. The analysis of metabolic profiles allows an efficient evaluation of liver graft preservation quality and the functional recovery during reperfusion.

The first study applying ${ }^{1} \mathrm{H}$ NMR analysis to bile produced during NMP was published by Habib et al. [58]. This study revealed several changes in biliary constituents, between bile produced during retrieval and perfusion, as follows: (i) the concentration of bile acids, lactate, glucose and phosphatidylcholine increased, while (ii) the concentration of acetate decreased. These changes were more pronounced in DCD rabbit liver grafts compared to DBD grafts, although this did not reach statistical significance [58]. These metabolites may be potential markers of the extent of WI injury and the functional activity of machine-perfused liver grafts.

Previously, Fontes et al. described a new preservation modality for the liver, combining subnormothermic MP (SNMP; $\sim 2{ }^{\circ} \mathrm{C}$ ) with hemoglobin-based oxygen carrier (HBOC) solution in a porcine orthotopic Tx model [60], analyzing over 600 tissue, perfusate and bile metabolites by GC-MS. The results revealed sustained metabolic activity (gluconeogenesis, albumin secretion, branched-chain amino acid secretion, urea production and ROS scavenging) during MP. Bile analysis over a 5-day period suggested that hydrophilic bile was secreted in the SNMP group, in contrast to hydrophobic bile documented in the SCS group. MP at $21^{\circ} \mathrm{C}$ with the HBOC solution significantly improved liver preservation compared to SCS [60].

Later, Liu et al. proposed that the alanine and histidine measured by ${ }^{1} \mathrm{H}$ NMR in HMP perfusate estimated WI injury in porcine liver grafts, and might be potential biomarkers of liver viability [59].

More recently, the metabolomic profiles, obtained by NMR, of back-table biopsies were significantly different in liver grafts with EAD [67]. The best discriminative metabolites, lactate and phosphocholine, were significantly associated with graft dysfunction, with excellent accuracy. The authors proposed the possibility of assessing the efficiency of graft resuscitation on MP by using these two markers in future studies [67]. Identifying metabolic biomarkers may enable the use of older donors and donors with longer ischemic times.

The first use of NMR spectroscopy on human liver samples was reported in 2005, determining metabolic profiles before organ retrieval, during HMP and after Tx [62]. The revealed variations in donor livers were consistent in most donors. First, GPC decreased in the majority of livers, suggesting increased cell turnover. Interestingly, in the graft that developed PGD, GPC remained stable, probably reflecting a lower degree of cellular activity, and therefore this substance might be a new biomarker for liver function [62].

Bruinsma et al. demonstrated the significant potential of MP combined with metabolomics as a clinical instrument for the assessment of preserved livers [63]. They applied SNMP $\left(21^{\circ} \mathrm{C}\right)$ on discarded human livers and determined changes by means of metabolic profiling with GC-MS and LC-MS, observing improvements in energetic cofactors and redox shifts, as well as the reversal of ischemia-induced alterations in specific pathways, including lactate metabolism and Krebs cycle intermediates. By this metabolomics approach, livers with similar metabolic patterns clustered based on the degree of injury [63]. This could help to identify organs that are suitable for Tx and those that should be discarded.

Karimian et al. compared the metabolomics of discarded steatotic human livers during $3 \mathrm{~h}$ of SNMP and NMP [64]. They found that steatotic livers replenish ATP storages more efficiently during SNMP than NMP. However, there is a significant depletion of glutathione during SNMP, likely due to the inability to overcome the high energy threshold needed for glutathione synthesis, highlighting the increased levels of oxidative stress in steatotic livers [64]. This study demonstrated that SNMP and NMP produce significantly different metabolomic profiles in liver grafts. More knowledge is needed to maximize the potential of both organ resuscitation techniques. 
Raigani et al. recently analyzed the use of NMP in combination with metabolic profiling to elucidate the deficiencies in metabolic pathways in steatotic livers [65]. During NMP, energy cofactors increased in steatotic livers to a similar extent as in normal livers, but a significant lack in anti-oxidant capacity, efficient energy utilization and lipid metabolism was observed. Steatotic livers appeared to oxidize fatty acids at a higher rate, but favored ketone body production rather than energy regeneration via the Krebs cycle, leading to a slower lactate clearance and therefore higher transaminase levels in steatotic livers [65]. Currently, the lack of standard criteria for determining the graft suitability for Tx after MP remains a significant limiting factor as regards the clinical use of discarded human livers.

In 2020, Xu et al. proposed a small panel of metabolites involved in the purine pathway as promising biomarkers for the determination of human liver tissue quality before liver Tx [66]. Higher ratios of adenosine monophosphate/urate, adenine/urate, hypoxanthine/urate and alanine aminotransferase were associated with inferior graft quality (DBD vs. DCD) and outcomes (early graft function vs. EAD) post Tx. Moreover, a superior prediction ability as compared to a combination of conventional liver function and risk markers is proposed [66].

\section{Conclusions}

Innovative techniques of metabolic profiling, including NMR, GS-MS and LC-MS, have identified key pathways and mechanisms involved in organ damage during WI and CI, as well as IRI occurring during solid organ preservation. A growing number of experimental studies claimed metabolomics to be a promising tool for the assessment of graft quality as an original and reliable method, and which may easily be implemented in daily hospital routine. Although large-scale trials are needed, MP combined with metabolomics appears to be a potent tool for characterizing potential biomarkers to estimate graft-related outcomes prior to Tx. Moreover, biomarkers found in the perfusate, bile or urine are advantageous over organ biopsies, for being non-invasive and thus enabling more frequent and objective sampling. The currently available evidence on metabolic profiling during graft preservation suggests improved graft quality maintenance by HMP compared to traditional SCS, since significant metabolic activity is absent during SCS but not during HMP. Therefore, the regeneration of important metabolites, such as high-energy phosphate nucleotides, following a period of hypothermic perfusion in large, clinically related animal models has been proven to be feasible. HMP is able to support organ metabolism, and seems promising especially for long-term preservation. Other MP techniques (NMP and SNMP) revealed promising results too; however, further studies are necessary since the debate over the role of optimal preservation temperature continues. Moreover, more studies should focus on metabolic changes over time. In the future, we should progress toward organ-tailored preservation, whereby high-risk grafts can undergo assessment by metabolic profiling and re-conditioning prior to Tx; therefore, the maintenance of metabolic activity and organ function during preservation is an important factor. There is still a need for universal analytical techniques that are able to accurately-with appropriate sensitivity and specificity-identify and quantify the complete scope of metabolites in biological samples, thus enabling implementation in routine clinical practice.

Supplementary Materials: Supplementary materials can be found at http://www.mdpi.com/1422-0067/21/18/ 6607/s1.

Author Contributions: P.S. (Philipp Stiegler) was responsible for the study concept, design and critical revision of the drafted manuscript. M.K., V.Z., P.S. (Peter Schemmer), B.L. and K.S. were responsible for the literature review, interpretation and drafting of the manuscript. All authors have read and agreed to the published version of the manuscript.

Funding: This research received no external funding.

Conflicts of Interest: The authors declare no conflict of interest. 


\section{Abbreviations}

$\begin{array}{ll}\text { ATP } & \text { adenosine triphosphate } \\ \text { CI } & \text { cold ischemia } \\ \text { DBD } & \text { donation after brain death } \\ \text { DCD } & \text { donation after circulatory death } \\ \text { DGF } & \text { delayed graft function } \\ \text { DMA } & \text { dimethylamine } \\ \text { EAD } & \text { early allograft dysfunction } \\ \text { EC } & \text { Euro-Collins solution } \\ \text { ECD } & \text { extended criteria donor } \\ \text { GC-MS } & \text { gas chromatography-mass spectrometry } \\ \text { GPC } & \text { glycerophosphocholine } \\ \text { GPE } & \text { glycerophosphorylethanolamine } \\ \text { HMP } & \text { hypothermic machine perfusion } \\ \text { IGF } & \text { immediate graft function } \\ \text { IRI } & \text { ischemia-reperfusion injury } \\ \text { LC-MS } & \text { liquid chromatography-mass spectrometry } \\ \text { MP } & \text { machine perfusion } \\ \text { NMP } & \text { normothermic machine perfusion } \\ \text { NMR } & \text { nuclear magnetic resonance } \\ \text { PEG } & \text { polyethylene glycol } \\ \text { PO } & \text { partial pressure of oxygen } \\ \text { ROS } & \text { reactive oxygen species } \\ \text { SCS } & \text { static cold storage } \\ \text { SERCA } & \text { sarcoplasmic reticulum calcium adenosine triphosphatase } \\ \text { SNMP } & \text { subnormothermic machine perfusion } \\ \text { TMAO } & \text { trimethylamine-N-oxide } \\ \text { Tx } & \text { transplantation } \\ \text { UW } & \text { University of Wisconsin solution } \\ \text { WI } & \text { warm ischemia } \\ & \end{array}$

\section{References}

1. Desai, C.S.; Gerber, D.A. Concise review of machine perfusion in liver transplantation. World J. Hepatol. 2020, 12, 6-9.

2. Black, C.K.; Termanini, K.M.; Aguirre, O.; Hawksworth, J.S.; Sosin, M. Solid organ transplantation in the 21st century. Ann. Transl. Med. 2018, 6, 409.

3. Choi, J.; Bano, A.; Azzi, J. Biomarkers in Solid Organ Transplantation. Clin. Lab. Med. 2019, 39, 73-85.

4. Tingle, S.J.; Figueiredo, R.S.; Moir, J.A.; Goodfellow, M.; Talbot, D.; Wilson, C.H. Machine perfusion preservation versus static cold storage for deceased donor kidney transplantation. Cochrane Database Syst. Rev. 2019, 3, CD011671.

5. Kvietkauskas, M.; Leber, B.; Strupas, K.; Stiegler, P.; Schemmer, P. Machine Perfusion of Extended Criteria Donor Organs: Immunological Aspects. Front. Immunol. 2020, 11, 192.

6. Boteon, Y.; Afford, S.C.; Mergental, H. Pushing the Limits: Machine Preservation of the Liver as a Tool to Recondition High-Risk Grafts. Curr. Transplant. Rep. 2018, 5, 113-120.

7. Weissenbacher, A.; Vrakas, G.; Nasralla, D.; Ceresa, C.D.L. The future of organ perfusion and re-conditioning. Transpl. Int. 2019, 32, 586-597.

8. Czigany, Z.; Lurje, I.; Schmelzle, M.; Schoning, W.; Ollinger, R.; Raschzok, N.; Sauer, I.M.; Tacke, F.; Strnad, P.; Trautwein, C.; et al. Ischemia-Reperfusion Injury in Marginal Liver Grafts and the Role of Hypothermic Machine Perfusion: Molecular Mechanisms and Clinical Implications. J. Clin. Med. 2020, 9, 846. [CrossRef]

9. James, H.; Southard, M.D.A.; Folkert, O.; Belzer, M.D. Organ Preservation. Annu. Rev. Med. 1995, 46, $235-247$.

10. Guy, A.J.; Nath, J.; Cobbold, M.; Ludwig, C.; Tennant, D.A.; Inston, N.G.; Ready, A.R. Metabolomic analysis of perfusate during hypothermic machine perfusion of human cadaveric kidneys. Transplantation 2015, 99, 754-759. 
11. Nath, J.; Smith, T.B.; Patel, K.; Ebbs, S.R.; Hollis, A.; Tennant, D.A.; Ludwig, C.; Ready, A.R. Metabolic differences between cold stored and machine perfused porcine kidneys: A (1)H NMR based study. Cryobiology 2017, 74, 115-120.

12. Jia, J.; Nie, Y.; Li, J.; Xie, H.; Zhou, L.; Yu, J.; Zheng, S. A Systematic Review and Meta-Analysis of Machine Perfusion vs. Static Cold Storage of Liver Allografts on Liver Transplantation Outcomes: The Future Direction of Graft Preservation. Front. Med. 2020, 7, 135. [CrossRef]

13. De Vries, Y.; Berendsen, T.A.; Fujiyoshi, M.; Berg, A.P.V.D.; Blokzijl, H.; De Boer, M.T.; Van Der Heide, F.; De Kleine, R.H.; Van Leeuwen, O.B.; Matton, A.P.M.; et al. Transplantation of high-risk donor livers after resuscitation and viability assessment using a combined protocol of oxygenated hypothermic, rewarming and normothermic machine perfusion: Study protocol for a prospective, single-arm study (DHOPE-COR-NMP trial). BMJ Open 2019, 9, e028596.

14. Mohan, S.; Chiles, M.C.; Patzer, R.E.; Pastan, S.O.; Husain, S.A.; Carpenter, D.J.; Dube, G.K.; Crew, R.J.; Ratner, L.E.; Cohen, D.J. Factors leading to the discard of deceased donor kidneys in the United States. Kidney Int. 2018, 94, 187-198.

15. Dirito, J.R.; Hosgood, S.A.; Tietjen, G.T.; Nicholson, M.L. The future of marginal kidney repair in the context of normothermic machine perfusion. Am. J. Transplant. 2018, 18, 2400-2408.

16. Bellini, M.I.; D'Andrea, V. Organ preservation: Which temperature for which organ? J. Int. Med. Res. 2019, 47, 2323-2325.

17. Nicholson, J.K.; Lindon, J.C.; Holmes, E. 'Metabonomics': Understanding the metabolic responses of living systems to pathophysiological stimuli via multivariate statistical analysis of biological NMR spectroscopic data. Xenobiotica 1999, 29, 1181-1189.

18. Attard, J.A.; Dunn, W.B.; Mergental, H.; Mirza, D.F.; Afford, S.C.; Perera, M. Systematic Review: Clinical Metabolomics to Forecast Outcomes in Liver Transplantation Surgery. OMICS 2019, 23, 463-476.

19. Wishart, D.S. Metabolomics: The principles and potential applications to transplantation. Am. J. Transplant. 2005, 5, 2814-2820.

20. Hauet, T.; Baumert, H.; Gibelin, H.; Hameury, F.; Goujon, J.M.; Carretier, M.; Eugene, M. Noninvasive monitoring of citrate, acetate, lactate, and renal medullary osmolyte excretion in urine as biomarkers of exposure to ischemic reperfusion injury. Cryobiology 2000, 41, 280-291.

21. Lee, C.; Lee, J.S.; Woo, C.; Kim, S. High-Resolution Magic Angle Spinning Nuclear Magnetic Resonance Spectroscopy for the Metabolic Assessment of Acute Rejection After Cardiac Transplantation in Rats. Transplant. Proc. 2017, 49, 1935-1941.

22. Bonneau, E.; Tetreault, N.; Robitaille, R.; Boucher, A.; De Guire, V. Metabolomics: Perspectives on potential biomarkers in organ transplantation and immunosuppressant toxicity. Clin. Biochem. 2016, 49, 377-384.

23. Lin, F.; Ou, Y.; Huang, C.Z.; Lin, S.Z.; Ye, Y.B. Metabolomics identifies metabolite biomarkers associated with acute rejection after heart transplantation in rats. Sci. Rep. 2017, 7, 15422.

24. Moher, D.; Liberati, A.; Tetzlaff, J.; Altman, D.G. Preferred reporting items for systematic reviews and meta-analyses: The PRISMA statement. Int. J. Surg 2010, 8, 336-341.

25. Lei, I.; Wang, Z.; Chen, Y.E.; Ma, P.X.; Huang, W.; Kim, E.; Lam, H.Y.; Goldstein, D.R.; Aaronson, K.D.; Pagani, F.D.; et al. "The Secret Life of Human Donor Hearts": An Examination of Transcriptomic Events During Cold Storage. Circ. Hear. Fail. 2020, 13, e006409.

26. Que, W.; Hu, X.; Fujino, M.; Terayama, H.; Sakabe, K.; Fukunishi, N.; Zhu, P.; Yi, S.-Q.; Yamada, Y.; Zhong, L.; et al. Prolonged cold ischemia time in mouse heart transplantation using supercooling preservation. Transplantation 2019. [CrossRef]

27. Li, Y.; Zeng, Q.; Liu, G.; Du, J.; Gao, B.; Wang, W.; Zheng, Z.; Hu, S.; Ji, B. Development and Evaluation of Heartbeat: A Machine Perfusion Heart Preservation System. Artif. Organs 2017, 41, E240-E250.

28. Peltz, M.; He, T.-T.; Adams, G.A.; Koshy, S.; Burgess, S.C.; Chao, R.Y.; Meyer, D.M.; Jessen, M.E. Perfusion preservation maintains myocardial ATP levels and reduces apoptosis in an ex vivo rat heart transplantation model. Surgery 2005, 138, 795-805.

29. Rosenbaum, D.H.; Peltz, M.; Merritt, M.E.; Thatcher, J.E.; Sasaki, H.; Jessen, M.E. Benefits of Perfusion Preservation in Canine Hearts Stored for Short Intervals. J. Surg. Res. 2007, 140, 243-249. 
30. Rosenbaum, D.H.; Peltz, M.; DiMaio, J.M.; Meyer, D.M.; Wait, M.A.; Merritt, M.E.; Ring, W.S.; Jessen, M.E. Perfusion preservation versus static preservation for cardiac transplantation: Effects on myocardial function and metabolism. J. Hear. Lung Transplant. 2008, 27, 93-99.

31. Cobert, M.L.; Peltz, M.; West, L.M.; Jessen, M.E. Importance of organ preservation solution composition in reducing myocardial edema during machine perfusion for heart transplantation. Transplant. Proc. 2010, $42,1591-1594$.

32. Cobert, M.L.; Merritt, M.E.; West, L.M.; Jessen, M.E.; Peltz, M. Differences in regional myocardial perfusion, metabolism, MVO2, and edema after coronary sinus machine perfusion preservation of canine hearts. ASAIO J. 2011, 57, 481-486.

33. Cobert, M.L.; Peltz, M.; West, L.M.; Jessen, M.E.; Jessen, M.E. Glucose is an ineffective substrate for preservation of machine perfused donor hearts. J. Surg Res. 2012, 173, 198-205.

34. Cobert, M.L.; Peltz, M.; West, L.M.; Ayers, C.; Jessen, M.E.; Peltz, M. Metabolic characteristics of human hearts preserved for 12 hours by static storage, antegrade perfusion, or retrograde coronary sinus perfusion. J. Thorac. Cardiovasc. Surg. 2014, 148, 2310-2315.e1.

35. Martin, J.L.; Costa, A.S.H.; Gruszczyk, A.V.; Beach, T.E.; Allen, F.M.; Prag, H.A.; Hinchy, E.C.; Mahbubani, K.T.; Hamed, M.; Tronci, L.; et al. Succinate accumulation drives ischaemia-reperfusion injury during organ transplantation. Nat. Metab. 2019, 1, 966-974.

36. Young, K.; Dilling, D.F. The Future of Lung Transplantation. Chest 2019, 155, 465-473.

37. Meyer, K.C. Recent advances in lung transplantation. F1000Research 2018, 7, 1684. [CrossRef]

38. Pillai, R.P.; Buescher, P.C.; Pearse, D.B.; Sylvester, J.T.; Eichhorn, G.L. 31P NMR spectroscopy of isolated perfused lungs. Magn. Reson. Med. 1986, 3, 467-472.

39. Jayle, C.; Corbi, P.; Eugene, M.; Carretier, M.; Hebrard, W.; Menet, E.; Hauet, T. Beneficial effect of polyethylene glycol in lung preservation: Early evaluation by proton nuclear magnetic resonance spectroscopy. Ann. Thorac. Surg. 2003, 76, 896-902.

40. Peltz, M.; He, T.T.; Adams, G.A.t.; Chao, R.Y.; Meyer, D.M.; Jessen, M.E. Characterizing lung metabolism with carbon-13 magnetic resonance spectroscopy in a small-animal model: Evidence of gluconeogenesis during hypothermic storage. Transplantation 2005, 80, 417-420.

41. Peltz, M.; He, T.T.; Adams, G.A.t.; Chao, R.Y.; Jessen, M.E.; Meyer, D.M. Pyruvate-modified perfadex improves lung function after long-term hypothermic storage. J. Hear. Lung Transplant. 2005, 24, 896-903.

42. Benahmed, M.A.; Santelmo, N.; Elbayed, K.; Frossard, N.; Noll, E.; Canuet, M.; Pottecher, J.; Diemunsch, P.; Piotto, M.; Massard, G.; et al. The assessment of the quality of the graft in an animal model for lung transplantation using the metabolomics $1 \mathrm{H}$ high-resolution magic angle spinning NMR spectroscopy. Magn. Reson. Med. 2012, 68, 1026-1038.

43. Hsin, M.K.; Zamel, R.; Cypel, M.; Wishart, D.; Han, B.; Keshavjee, S.; Liu, M. Metabolic Profile of Ex Vivo Lung Perfusate Yields Biomarkers for Lung Transplant Outcomes. Ann. Surg. 2018, 267, 196-197.

44. Sharma, N.; Mahajan, A.; Qazi, Y.A. Marginal kidney transplantation: The road less traveled. Curr. Opin. Organ Transplant. 2019, 24, 92-96.

45. Richer, J.P.; Baumer, T.H.; Gibelin, H.; Ben Amor, I.; Hebrard, W.; Carretier, M.; Eugene, M.; Hauet, T. Evaluation of renal medulla injury after cold preservation and transplantation: Noninvasive determination of medullar damage by proton nuclear magnetic resonance spectroscopy of urine and plasma. Transplant. Proc. 2000, 32, 47-48.

46. Hauet, T.; Gibelin, H.; Godart, C.; Eugene, M.; Carretier, M. Kidney retrieval conditions influence damage to renal medulla: Evaluation by proton nuclear magnetic resonance (NMR) pectroscopy. Clin. Chem. Lab. Med. 2000, 38, 1085-1092.

47. Serkova, N.; Fuller, T.F.; Klawitter, J.; Freise, C.E.; Niemann, C.U. H-NMR-based metabolic signatures of mild and severe ischemia/reperfusion injury in rat kidney transplants. Kidney Int. 2005, 67, 1142-1151.

48. Buchs, J.B.; Lazeyras, F.; Ruttimann, R.; Nastasi, A.; Morel, P. Oxygenated hypothermic pulsatile perfusion versus cold static storage for kidneys from non heart-beating donors tested by in-line ATP resynthesis to establish a strategy of preservation. Perfusion 2011, 26, 159-165.

49. Bon, D.; Claire, B.; Thuillier, R.; Hebrard, W.; Boildieu, N.; Celhay, O.; Irani, J.; Seguin, F.; Hauet, T. Analysis of perfusates during hypothermic machine perfusion by NMR spectroscopy: A potential tool for predicting kidney graft outcome. Transplantation 2014, 97, 810-816. 
50. Nath, J.; Smith, T.; Hollis, A.; Ebbs, S.; Canbilen, S.W.; Tennant, D.A.; Ready, A.R.; Ludwig, C. (13)C glucose labelling studies using 2D NMR are a useful tool for determining ex vivo whole organ metabolism during hypothermic machine perfusion of kidneys. Transplant. Res. 2016, 5, 7.

51. Patel, K.; Smith, T.B.; Neil, D.A.H.; Thakker, A.; Tsuchiya, Y.; Higgs, E.B.; Hodges, N.J.; Ready, A.R.; Nath, J.; Ludwig, C. The Effects of Oxygenation on Ex Vivo Kidneys Undergoing Hypothermic Machine Perfusion. Transplantation 2019, 103, 314-322.

52. Darius, T.; Vergauwen, M.; Smith, T.B.; Patel, K.; Craps, J.; Joris, V.; Aydin, S.; Ury, B.; Buemi, A.; De Meyer, M.; et al. Influence of Different Partial Pressures of Oxygen During Continuous Hypothermic Machine Perfusion in a Pig Kidney Ischemia-reperfusion Autotransplant Model. Transplantation 2020, 104, 731-743.

53. Nath, J.; Guy, A.; Smith, T.B.; Cobbold, M.; Inston, N.G.; Hodson, J.; Tennant, D.A.; Ludwig, C.; Ready, A.R. Metabolomic perfusate analysis during kidney machine perfusion: The pig provides an appropriate model for human studies. PLoS ONE 2014, 9, e114818.

54. Busza, A.; Fuller, B.J.; Proctor, E. Evaluation of cold reperfusion as an indicator of viability in stored organs: A 31P NMR study in rat liver. Cryobiology 1994, 31, 26-30.

55. Changani, K.K.; Fuller, B.J.; Bell, J.D.; Bryant, D.J.; Moore, D.P.; Taylor-Robinson, S.D.; Davidson, B.R. Hepatic nucleotide triphosphate regeneration after hypothermic reperfusion in the pig model: An in vitro P-NMR study. Transplantation 1996, 62, 787-793.

56. Changani, K.K.; Fuller, B.J.; Bryant, D.J.; Bell, J.D.; Ala-Korpela, M.; Taylor-Robinson, S.D.; Moore, D.P.; Davidson, B.R. Non-invasive assessment of ATP regeneration potential of the preserved donor liver. A 31P MRS study in pig liver. J. Hepatol. 1997, 26, 336-342.

57. Gibelin, H.; Eugene, M.; Hebrard, W.; Malard, Y.; Carretier, M.; Hauet, T. Comparison of Euro-Collins and university of wisconsin solutions in the isolated perfused rat liver model: Evaluation by proton nuclear magnetic resonance spectroscopy. Transplant. Proc. 2000, 32, 2792-2793.

58. Habib, M.M.; Hafez, T.S.; Parkes, H.G.; Seifalian, A.M.; Fuller, B.J.; Davidson, B.R. A comparison of bile composition from heart-beating and non-heart-beating rabbit organ donors during normothermic extracorporeal liver perfusion: Experimental evaluation using proton magnetic resonance spectroscopy. Transplant. Proc. 2004, 36, 2914-2916.

59. Liu, Q.; Vekemans, K.; Van Pelt, J.; Pirenne, J.; Himmelreich, U.; Heedfeld, V.; Wylin, T.; Brassil, J.; Monbaliu, D.; Dresselaers, T. Discriminate liver warm ischemic injury during hypothermic machine perfusion by proton magnetic resonance spectroscopy: A study in a porcine model. Transplant. Proc. 2009, 41, 3383-3386.

60. Fontes, P.; Lopez, R.; van der Plaats, A.; Vodovotz, Y.; Minervini, M.; Scott, V.; Soltys, K.; Shiva, S.; Paranjpe, S.; Sadowsky, D.; et al. Liver preservation with machine perfusion and a newly developed cell-free oxygen carrier solution under subnormothermic conditions. Am. J. Transplant. 2015, 15, 381-394.

61. Lanir, A.; Jenkins, R.L.; Caldwell, C.; Lee, R.G.; Khettry, U.; Clouse, M.E. Hepatic transplantation survival: Correlation with adenine nucleotide level in donor liver. Hepatology 1988, 8, 471-475.

62. Duarte, I.F.; Stanley, E.G.; Holmes, E.; Lindon, J.C.; Gil, A.M.; Tang, H.; Ferdinand, R.; McKee, C.G.; Nicholson, J.K.; Vilca-Melendez, H.; et al. Metabolic assessment of human liver transplants from biopsy samples at the donor and recipient stages using high-resolution magic angle spinning $1 \mathrm{H}$ NMR spectroscopy. Anal. Chem. 2005, 77, 5570-5578.

63. Bruinsma, B.G.; Sridharan, G.V.; Weeder, P.D.; Avruch, J.H.; Saeidi, N.; Ozer, S.; Geerts, S.; Porte, R.J.; Heger, M.; Van Gulik, T.M.; et al. Metabolic profiling during ex vivo machine perfusion of the human liver. Sci. Rep. 2016, 6, 22415.

64. Karimian, N.; Raigani, S.; Huang, V.; Nagpal, S.; Hafiz, E.O.A.; Beijert, I.; Mahboub, P.; Porte, R.J.; Uygun, K.; Yarmush, M.; et al. Subnormothermic Machine Perfusion of Steatotic Livers Results in Increased Energy Charge at the Cost of Anti-Oxidant Capacity Compared to Normothermic Perfusion. Metabolites 2019, 9, 246. [CrossRef]

65. Raigani, S.; Karimian, N.; Huang, V.; Zhang, A.M.; Beijert, I.; Geerts, S.; Nagpal, S.; Hafiz, E.O.A.; Fontan, F.M.; Aburawi, M.M.; et al. Metabolic and lipidomic profiling of steatotic human livers during ex situ normothermic machine perfusion guides resuscitation strategies. PLOS ONE 2020, 15, e0228011. 
66. Xu, J.; Hassan-Ally, M.; Casas-Ferreira, A.M.C.; Suvitaival, T.; Ma, Y.; Vilca-Melendez, H.; Rela, M.; Heaton, N.; Jassem, W.; Legido-Quigley, C.; et al. Deregulation of the Purine Pathway in Pre-Transplant Liver Biopsies Is Associated with Graft Function and Survival after Transplantation. J. Clin. Med. 2020, 9, 711. [CrossRef]

67. Faitot, F.; Besch, C.; Battini, S.; Ruhland, E.; Onea, M.; Addeo, P.; Woehl-Jaeglé, M.-L.; Ellero, B.; Bachellier, P.; Namer, I.-J. Impact of real-time metabolomics in liver transplantation: Graft evaluation and donor-recipient matching. J. Hepatol. 2018, 68, 699-706.

(C) 2020 by the authors. Licensee MDPI, Basel, Switzerland. This article is an open access article distributed under the terms and conditions of the Creative Commons Attribution (CC BY) license (http://creativecommons.org/licenses/by/4.0/). 